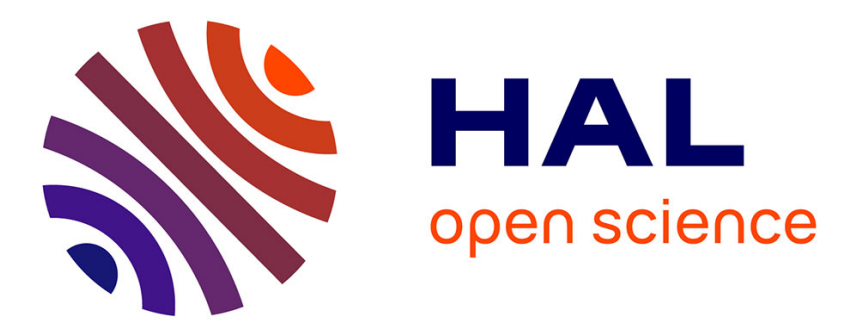

\title{
Cardio-respiratory and subjective strains sustained by paraplegic subjects, when travelling on a cross slope in a manual wheelchair (MWC)
}

Benoît Pierret, Kévin Desbrosses, Jean Paysant, Jean-Pierre Meyer

\section{- To cite this version:}

Benoît Pierret, Kévin Desbrosses, Jean Paysant, Jean-Pierre Meyer. Cardio-respiratory and subjective strains sustained by paraplegic subjects, when travelling on a cross slope in a manual wheelchair (MWC). Applied Ergonomics, 2014, 45 (4), pp.1056-1062. 10.1016/j.apergo.2014.01.002 . hal01070917

\section{HAL Id: hal-01070917 \\ https://hal.science/hal-01070917}

Submitted on 7 Oct 2014

HAL is a multi-disciplinary open access archive for the deposit and dissemination of scientific research documents, whether they are published or not. The documents may come from teaching and research institutions in France or abroad, or from public or private research centers.
L'archive ouverte pluridisciplinaire HAL, est destinée au dépôt et à la diffusion de documents scientifiques de niveau recherche, publiés ou non, émanant des établissements d'enseignement et de recherche français ou étrangers, des laboratoires publics ou privés. 


\section{Cardio-respiratory and subjective strains sustained by paraplegic subjects, when travelling on a cross slope in a Manual Wheelchair}

Benoît Pierret $^{\text {a,b,c }}$, Kévin Desbrosses ${ }^{\text {a }}$, Jean Paysant ${ }^{\mathrm{b}}$, Jean-Pierre Meyer ${ }^{\mathrm{a}}$.

${ }^{a}$ Institut National de Recherche et de Sécurité, Vandoeuvre les Nancy cedex, 54519, 1 rue du Morvan, CS 60027, France. (kevin.desbrosses@inrs.fr ; meyer@inrs.fr)

b Institut Régional de Médecine Physique et de Réadaptation, Nancy cedex, 54042, 75 boulevard Lobau, CS 34209, France. (jean.paysant@ugecamne.fr)

${ }^{c}$ Centre de Ressources, d'Expertise et de Performance Sportives, Essey les Nancy, 54271, 1 Av Foch, BP 30020, France. (benoit.pierret@yahoo.fr)

corresponding author :

Jean-Pierre Meyer

INRS, 1 rue du morvan, 54519,

Vandoeuvre les Nancy, France

Tel 33/3 $83502054 \quad$ Fax : $33 / 383502185$

meyer@inrs.fr 


\begin{abstract}
The aim of this study was to quantify cardiac, energetic and subjective strains during manual wheelchair (MWC) travel on cross slopes (Cs). 25 paraplegics achieved eight $300 \mathrm{~m}$ propulsion tests combining $4 \mathrm{Cs}(0,2,8$ and $12 \%)$ and 2 velocities $\left(\mathrm{Vi}=0.97 \mathrm{~m} . \mathrm{s}^{-1}, \mathrm{Vc}\right.$ "comfortable"). Heart rate and oxygen uptake were recorded continuously. Subjective rating (RPE) was made on completion of each test. Vc exceeds Vi for all Cs. Cardiac and energetic strains at Vc also exceed those at Vi $(\mathrm{p}<0.01)$. Mean cardiac cost (in bpm) at $\mathrm{Vc}$ is 34 $(\mathrm{SD}=13) \mathrm{bpm}$ for a $0 / 2 \%$ Cs and 55 (18) bpm for a $12 \%$ Cs. Mean energetic cost (in $\mathrm{J}^{-\mathrm{m}^{-1}} \cdot \mathrm{kg}^{-}$ ${ }^{1}$ ) is $1.20(0.38)$ and $2.76(0.97)$ for respectively $0 / 2 \%$ and $12 \% \mathrm{Cs}$ at $\mathrm{Vi}$ and, at $\mathrm{Vc} 1.50(0.43)$ and 3.37 (1.43) for $0 / 2 \%$ and $12 \%$ Cs respectively. Subjective rating was considered as moderate for a $12 \%$ Cs. MWC users with high level injuries travel faster as those with low level injuries. Strain increase is linear for Cs from $0 \%$ to $12 \%$. The results suggest that $2 \%$ Cs is generally acceptable, while $8 \%$ would be a critical threshold.
\end{abstract}

Keywords : Wheelchair, Cross Slope, Strains 


\section{Introduction}

In France, nearly 200,000 disabled persons use a manual wheelchair (MWC) and live at home (Vignier et al, 2008). Travelling difficulties are one of the determining factors in nonintegration or occupational exclusion of persons in MWC (Lidal et al, 2007; Van Velzen et al, 2009). Environmental unsuitability amplifies a MWC's initial constraints and requires greater cardio-respiratory and muscular exertion on behalf of persons in relation to their physiological capacities (Collins et al, 2010, Meyers et al, 2002). Although the peak oxygen uptakes of MWC sportsmen may exceed $35 \mathrm{ml} \cdot \mathrm{kg}^{-1} \cdot \mathrm{min}^{-1}$ (Bhambhani, 2002; Haisma et al., 2006; Huonker et al., 1998; Van der Woude et al., 2001), these capacities are less than 20, even 15 ml.kg-1 $\min ^{-1}$ for many users (Figoni, 1984; Haisma et al., 2006; Tahamont et al., 1986). Additional constraints like cross slope (Cs) which is the slope that is perpendicular to the direction of travel, can thus degrade MWC user social life and state of health by increasing musculo-skeletal disorders (Burnham et al, 1994; Mercer et al, 2006; Van Drongelen et al., 2006). Indeed, Cs causes gyratory action of the chair's front wheels, which generate a force that tends to pull the "subject-wheelchair" combination to the lower side and requires users to fight against this force in order to keep a straight course (Cooper, 1990; Van der Woude et al., 2001).

A $2 \%$ Cs limit is regulatory in many countries (McMillen et al., 1999), but this may not always be respected. Furthermore, no result really prompts justification of this $2 \%$ established Cs limit. In fact few studies have focused on MWC movements on a Cs. A recent review by Cooper et al. (2011) only lists five such studies. Three were mainly directed towards the biomechanical aspects of wheelchair propulsion (Brubaker et al., 1986; Chesney and Axelson, 1996; Richter et al., 2007). The other two addressed the problems of travelling on varied surfaces, some with a Cs, experienced by populations suffering from various pathologies (Longmuir et al., 2003; Kockelman et al., 2001). Only the Brubaker et al. (1986) and the Kockelman et al. (2001) studies included physiological measurements. Despite the disparity in these studies an overview reveals that Cs limits of between 16 and $20 \%$ for short distances (Chesney and Axelson, 1996) and for longer journeys, a 4\% Cs is acceptable for all users and a more critical 10\% limit should never be exceeded (Kockelman et al, 2001). These values are very far from the $2 \%$ regulatory limit (McMillen et al., 1999).

With a view to proposing a rationalised allowable Cs, the present study sets out to determine the cardio-respiratory and subjective strains involved in MWC travel under real propulsion 
conditions on different Cs and at two travelling velocities for a large number of regular MWC users.

\section{Equipment and Methods}

The study was conducted in the occupational physiology laboratory at the Institut National de Recherche et de Sécurité (INRS) jointly with the Institut Régional de médecine physique et de Réadaptation (IRR) both located in Nancy in the eastern part of France.

\subsection{Subjects}

The 25 volunteer subjects were recruited from patients monitored at the IRR, based on the following inclusion criteria: men, paraplegic, adult and of working age (18-65 years old), travelling independently and regularly in a MWC for more than 6 months. Injury level was defined as "high" for injuries at or higher than the $6^{\text {th }}$ thoracic vertebra, and as "low" for injuries of the $7^{\text {th }}$ thoracic vertebra or lower who have functional abdominal muscles. Subjects have no contraindication (cardiovascular, pulmonary, muscular, skin and/or developing general pathologies). They were informed of the study protocol and gave their written consent. The study received approval from the local ethical committee.

\subsection{Protocol}

Two tests were performed: a test involving sub-maximal exertion on an arm ergocycle and a propulsion track test. The arm cranking test was conducted on a first half-day dedicated to the study inclusion medical examination. A second full-day was dedicated to the track propulsion testing. At least two rest days separated the two test sessions to eliminate fatigue from the cranking test. Both tests were conducted under medical surveillance.

\subsubsection{Cranking test}

The sub-maximal arm cranking test was conducted on an arm ergocycle fitted with a magnetic induction braking system ensuring power control (Upper Body Cycle, Kardiomed ${ }^{\circledR}$ ). This test allowed to estimate the peak oxygen uptake $\left(\mathrm{VO}_{2} \mathrm{max}\right)$ of the subjects through extrapolating the relationship between $\mathrm{HR}$ and $\mathrm{VO}_{2}$ to their HRmax (Paré et al., 1993). The test started with a 2-minute, $25 \mathrm{~W}$ warm-up step before continuing in 2-minute steps with an increase of $10 \mathrm{~W}$ per step. Pedalling frequency was 50 rotations per minute. The test was stopped when the subjects reached $85 \%$ of their theoretical maximum heart rate (HRmax $=220-$ age in years) (Wilmore and Costill, 2004). 


\subsubsection{Propulsion test}

The propulsion test was performed on a $50 \mathrm{~m}$ long test track specially designed for the study. Two opposite straights were each $24 \mathrm{~m}$ long and the subjects travelled back and forth on these. The track was $1.2 \mathrm{~m}$ wide in compliance with wheelchair route minimum width. The wooden track was covered with surfacing material (Tarasafe super, Gerflor ${ }^{\circledR}$ ) with a dynamic friction coefficient of 0.4 (ua) close to that of an average asphalt pavement ( 0.38 u.a.). The track Cs was mechanically adjusted and checked using an electronic level (Laser Cross Liner Novipro, Bosch ${ }^{\circledR}$ ).

The subjects were submitted to 8 experimental conditions combining 4 Cs (0,2, 8 and 12\%) and 2 velocities: one imposed $\left(\mathrm{Vi}=0.97 \mathrm{~m} \cdot \mathrm{s}^{-1}\right)$, the other so-called "comfortable" $(\mathrm{Vc})$, chosen by the subjects themselves. Under each of the 8 conditions, the subjects undertook 6 laps $(300 \mathrm{~m})$ around the track; this distance insured physiological parameter stability (Wilmore and Costill, 2004). The order of testing of the 8 conditions was random. The propulsion method was free. The travelling direction conditions the dominant body side in the most demanding side i.e. in the steeper Cs. The subjects used their own MWC. Wheel diameter was 24 inches and tyres were inflated to a pressure of 8 bar.

The imposed velocity $\mathrm{Vi}\left(0.97 \mathrm{~m} . \mathrm{s}^{-1}\right)$, constant for the $4 \mathrm{Cs}$, was monitored by electroluminescent diodes fixed every 2 meters along the walls bordering the test track. The subjects adjusted the travelling velocity based on delayed lighting of the diodes. The Vi and the Vc, chosen by the subject, were measured by timing at each lap. Temperature and relative humidity were measured for each half-day using a portable hygro-thermometer (RH70, Omega $\left.^{\circledR}\right)$.

\subsection{Measured variables}

The measured physiological parameters were heart rate (HR in bpm), oxygen uptake $\left(\mathrm{VO}_{2}\right.$ in $\left.\mathrm{ml} \cdot \mathrm{kg}^{-1} \cdot \mathrm{min}^{-1}\right)$ and carbon dioxide production $\left(\mathrm{VCO}_{2}\right.$ in $\left.\mathrm{ml} \cdot \mathrm{kg}^{-1} \cdot \mathrm{min}^{-1}\right)$. Subjective strain was assessed based on the Rating of Perceived Exertion (RPE) scale (Borg 1998).

HR was measured continuously for the whole day using a cardio frequency meter (Polar ${ }^{\circledR}, S$ 810 i) with a count integration time of $15 \mathrm{~s}$. Cardiac strain parameters were: a) the HR, b) the absolute cardiac cost (ACC in bpm), which is the difference between the mean HR during the test and the HR when seated and at rest, c) the relative cardiac cost (RCC in \%), which expresses the percentage strain of the HR reserve (HRR), which is the difference between the subject's HRmax and his HR at rest (Wilmore and Costill, 2004). The RCC is determined by the ACC/HRR ratio. 
Respiratory parameters were recorded using a cycle-to-cycle gas analyser telemetric system $\left(\right.$ Cosmed $\left.\mathrm{K}_{4} \mathrm{~b}^{2 \circledR}\right)$. The respiratory parameters processed were: a) the $\mathrm{VO}_{2}$, b) the energetic cost per metre travelled and per $\mathrm{kg}$ weight $\left(\mathrm{ECmkg}\right.$ in $\left.\mathrm{J}_{\mathrm{m}} \mathrm{m}^{-1} \cdot \mathrm{kg}^{-1}\right)$ and, c) the relative energetic cost ( $\mathrm{REC}$ in \%). The ECmkg is the product of the oxygen cost $\left(\mathrm{cVO}_{2}\right)$ by the energy equivalent of one litre of oxygen $\left(\mathrm{k}\right.$ in $\left.\mathrm{kJ} . \mathrm{l}^{-1}\right)$ divided by the velocity and the weight $(\mathrm{P}=$ subject+MWC weight in $\mathrm{kg}) ; \mathrm{ECmkg}=\mathrm{cVO}_{2} \cdot \mathrm{k} / \mathrm{V} . \mathrm{P}$. The oxygen cost $\left(\mathrm{cVO}_{2}\right.$ in $\left.\mathrm{ml}^{\mathrm{kg}} \mathrm{kg}^{-1} \cdot \mathrm{min}^{-1}\right)$ is the difference between the mean $\mathrm{VO}_{2}$ during the test and the $\mathrm{VO}_{2}$ at rest. The energy equivalent of 1 litre of oxygen is calculated using the equation $\mathrm{k}=16.6+4.6 \mathrm{RQ}$, in which the respiratory quotient (RQ) is the ratio $\mathrm{VCO}_{2} / \mathrm{VO}_{2}$. The REC represents the fraction of the oxygen reserve involved in the exercise. REC is the ratio between the $\mathrm{cVO}_{2}$ and the oxygen reserve $\left(\mathrm{VO}_{2} \mathrm{R}\right)$, equal to $\mathrm{VO}_{2}$ max- $\mathrm{VO}_{2}$ rest (Wilmore and Costill 2004).

Subjective strain was obtained using the RPE (Borg, 1998) scale. A global and 5 local assessments (back, shoulders, upper limbs) were asked for at the end of each track test.

\subsection{Statistical analysis}

Results are expressed by their mean and standard deviation (SD) shown in brackets for the 25 subjects. Student $\mathrm{t}$ tests on the paired samples allow us to analyse the effects of Cs on: travelling velocity ( $\mathrm{Vc}$ and $\mathrm{Vi}$ ), $\mathrm{HR}, \mathrm{VO}_{2}$ and subjective strains. Distribution normality was checked and achieved by variable transform if needed. Three-factor variance analyses (ANOVA) with correction for co-variable effects qualify the effects of Cs, velocity and injury level on the cardiac, energetic and subjective strains. Simple and multiple regression models based on the least square method were used to establish the relationships between the different variables. A $5 \%$ significance threshold was retained $(\mathrm{p}<0.05)$. Statistical analyses were conducted using Statgraphics ${ }^{\circledR}$ Centurion XVI software.

\section{Results}

\subsection{Subject characteristics}

Table 1 displays the means, SD and peak values of age, height, weight, body mass index (BMI) and the injury age and level for the 25 subjects.

\section{Table 1 about here}


The MWC mean weight was 14.6 (2.1) $\mathrm{kg}$ and $3 / 4$ of the subjects had been using a wheelchair for over 4 years. No Table 1 characteristic is significantly different ( $>0.1)$ in relation to the injury's "low" or "high" level. In particular, the 15 subjects with "low" level injuries display a $\mathrm{VO}_{2} \mathrm{max}$ of 25.6 (6.0) $\mathrm{ml} \cdot \mathrm{kg}^{-1} \cdot \mathrm{min}^{-1}$ and a HR at rest of 71.3 (3.1) bpm that are not statistically different $(\mathrm{p}>0.15)$ to those of the 10 subjects with "high" level injuries, who display a $\mathrm{VO}_{2} \max$ of $24.0(4.8) \mathrm{ml} \cdot \mathrm{kg}^{-1} \cdot \mathrm{min}^{-1}$ and a HR at rest of 73.8 (3.7) bpm. The mean $\mathrm{VO}_{2}$ at rest is $4.1(0.9) \mathrm{ml} \cdot \mathrm{kg}^{-1} \cdot \mathrm{min}^{-1}$ and is not significantly altered by the injury level either.

\subsection{Experimental conditions}

- The sub-maximal exertion and track tests were conducted under conditions of thermal comfort; air temperature and relative humidity mean values were 20.5 (1.7) ${ }^{\circ} \mathrm{C}$ and 42 (14) \%. Cross slope checking showed that Cs values were slightly, but systematically, higher than their theoretical values. The mean error was $0.4 \%$ and never exceeded $0.8 \%$.

- The imposed velocity Vi $\left(0.97 \mathrm{~m} . \mathrm{s}^{-1}\right)$ effective mean value was $0.94(0.03) \mathrm{m}_{\mathrm{s}} \mathrm{s}^{-1}$ and is the same at the $4 \mathrm{Cs}(\mathrm{p}>0.5)$. The mean "comfortable" velocity Vc was $1.26(0.25) \mathrm{m} . \mathrm{s}^{-1}$. Vc was stable from the second lap onwards under each Cs condition. It decreased significantly $\left(\mathrm{F}_{3.1169}=57 ; \mathrm{p}<0.001\right)$ when the Cs increased: $1.41(0.25)$ on the flat, $1.33(0.21)$ for $2 \%, 1.21$ (0.19) for $8 \%$ and $1.10(0.24) \mathrm{m} . \mathrm{s}^{-1}$ for $12 \% \mathrm{Cs}$. Vc is significantly related to the subject $\mathrm{VO}_{2} \max (\mathrm{t}=3.7 ; \mathrm{p}<0.001)$. For an increase of $5 \mathrm{ml} \cdot \mathrm{kg}^{-1} \cdot \mathrm{min}^{-1}$ in $\mathrm{VO}_{2} \mathrm{max}, \mathrm{Vc}$ increases by $0.08 \mathrm{~m} . \mathrm{s}^{-1}$. Surprisingly, the Vc of subjects with "high" level injuries $\left(1.25 \mathrm{~m} . \mathrm{s}^{-1}\right)$ is significantly higher $(\mathrm{p}<0.05)$ than that of subjects with "low" level injuries $\left(1.18 \mathrm{~m} . \mathrm{s}^{-1}\right)$. The mean total test times were 5.28 (0.18) minutes at $\mathrm{Vi}$ and comprised between $3.65(0.6)$ minutes for $0 \%$ slopes and 4.85 (1.45) minutes for $12 \%$ slopes at Vc. Total test time and Vc $(\mathrm{p}<0.01)$ are significantly $(\mathrm{p}<0.05)$ different between 0 and $2 \%$ Cs.

Among the 25 subjects, 5 were incapable of undertaking the last lap under all the experimental conditions. From the third to the sixth lap, there was no significant difference in either HR $\left(\mathrm{F}_{3.753}<0.1 ; \mathrm{p}>0.9\right)$ nor $\mathrm{VO}_{2}\left(\mathrm{~F}_{3.773}=0.6\right.$; $\left.\mathrm{p}>0.6\right)$. Moreover, for the 0 and $2 \% \mathrm{Cs}$ conditions, there was no significant difference in both $\mathrm{HR}$ and $\mathrm{VO}_{2}\left(\mathrm{~F}_{1.592}<0.6 ; \mathrm{p}>0.4\right)$. These observations led us to process only the data for laps 3,4 and 5 and to group the results of the physiological strains at 0 and $2 \%$ Cs denoted $0 / 2 \%$.

\section{3. Measured strains}

3.3.1 Cardiac strain 
The HR, ACC and RCC shown in Table 2 are all significantly altered by the velocity conditions $(F>95 ; p<0.001)$ and, for each velocity, by the 3 different $C s(F>92 ; p<0.001)$.

\section{Table 2 about here}

The ACC is related to the Cs (in \%) and the real travelling velocity (V in $\mathrm{m}^{-1}{ }^{-1}$ ) as follows:

$$
\begin{array}{cc}
\mathrm{ACC}=-7.1+2.3 \mathrm{Cs}+28.1 \mathrm{~V} & \text { Equation } 1 \\
\mathrm{n}=568 ; \mathrm{r}^{2}=0.44 &
\end{array}
$$

In Equation 1, the individual effects of $\mathrm{Cs}$ and $\mathrm{V}$ are significant $(\mathrm{p}<0.001)$. The $\mathrm{ACC}$ is increased by individual factors, such as user weight $(p<0.001)$, age $(p<0.001)$, injury age $(\mathrm{p}<0.001)$ and $\mathrm{VO}_{2} \max$ decrease $(\mathrm{p}<0.001)$.

\subsubsection{Energetic strains}

The $\mathrm{VO}_{2}$, ECmkg and relative energetic cost (REC) values presented in Table 3 are all significantly modified by the velocity conditions $\left(\mathrm{F}_{1.570}>20 ; \mathrm{p}<0.005\right)$ and by the Cs $\left(\mathrm{F}_{2.570}>108 ; \mathrm{p}<0.001\right)$ for each velocity.

\section{Table 3 about here}

The oxygen uptake $\left(\mathrm{VO}_{2}\right.$ in $\left.\mathrm{ml} \cdot \mathrm{kg}^{-1} \cdot \mathrm{min}^{-1}\right)$ is related to the $\mathrm{Cs}(\mathrm{Cs}$ in \%) and the real travelling velocity $\left(\mathrm{V}\right.$ in $\left.\mathrm{m} . \mathrm{s}^{-1}\right)$ as follows:

$$
\begin{aligned}
& \mathrm{VO}_{2}=-4.0+0.46 \mathrm{Cs}+7.4 \mathrm{~V} \quad \text { Equation } 2 \\
& \mathrm{n}=583 ; \mathrm{r}^{2}=0.52
\end{aligned}
$$

In Equation 2, the individual effects of $\mathrm{Cs}$ and $\mathrm{V}$ are significant $(\mathrm{p}<0.001)$. The energetic strain increases when individual factors, such as age $(\mathrm{p}<0.001)$ and BMI $(\mathrm{p}<0.001)$ increase or when physical activity $(\mathrm{p}<0.001)$, injury level $(\mathrm{p}<0.01)$ or $\mathrm{VO}_{2} \max (\mathrm{p}<0.001)$ decrease.

The mean respiratory quotient $(\mathrm{RQ})$ are significantly different for the three Cs studied $\left(\mathrm{F}_{2.579}\right.$ $=23 ; \mathrm{p}<0.001)$. For the $12 \% \mathrm{Cs}$, the RQ at Vc $(0.98)$ is significantly $(\mathrm{p}<0.01)$ higher than at $\mathrm{Vi}$ (0.93). Additionally, for the $0 / 2 \% \mathrm{Cs}$, the RQ does not change when laps are performed, while it increases regularly and significantly $(\mathrm{p}<0.01)$ for the $8 \%$ and $12 \%$ Cs. The RQ of half the subjects exceeds 1 at the end of the test at Vc on the 12\% Cs. The mean RQ of the subjects with a "low" level injury $(0.92)$ is significantly $(\mathrm{p}<0.02)$ higher than that of the subjects with a "high" level injury (0.89) and neither the Cs nor the velocity alters this difference. 


\subsubsection{Subjective strains}

The subjective rating results remain unaltered by the velocity $(p>0.4)$, but the Cs increases significantly the subject rating $(p<0.001)$. The mean estimation is $7.8(1.8)$ for the $0 / 2 \%, 9.9$ (2.6) for the $8 \%$ and 11.9 (3.4) for the $12 \%$ Cs, equivalent to very light, light and moderate on the Borg scale respectively. The RPE increases with BMI $\left(\mathrm{F}_{1.199}=5.5 ; \mathrm{p}<0.02\right)$. It is significantly $(\mathrm{p}<0.001)$ higher $(\mathrm{RPE}=9.9(0.6))$ for subjects with "low" level injuries than for those with "high" level injuries, who rated RPE as 8.5 (0.7). Finally, the Cs is only perceived at $8 \%$ and at $12 \%$. The ratio of dominant to non dominant side local RPE (shoulder + arm) remains 1 for the $0 \%$ and $2 \%$ Cs $(p>0.3)$ and becomes significantly $(\mathrm{p}<0.01)$ greater than 1 from the $8 \%$ Cs upwards. However, at 2\% Cs RPE of "low" level injured is significantly $(\mathrm{p}<0.005)$ higher than that of "high" level injured; 8.5 (0.5) vs $7.0(0.6)$.

\subsubsection{Strains variations}

Figure 1 illustrates the variations in the 3 strains (cardiac, energetic and subjective) at 2 velocities and 4 Cs studied.

\section{Figure 1 about here}

Results in figure 1 reveal a virtually linear variation in strains for Cs between $0 / 2 \%$ and $12 \%$. This illustrates the fact that, under the conditions of this study, the linear models representing Equations 1 and 2 are not improved by non-linear modelling.

\section{Discussion}

Our discussion will address in succession points concerning methodology, subject characteristics and travelling velocities before analysing the strain levels for different Cs and comparing these with data in the literature. At the end of this discussion, we propose a Cs limit model.

\subsection{Methodology}

Unlike the majority of studies published to date, the results of this work are based on a large number of paraplegic subjects (25) accustomed to travelling in a MWC. However, this subject "uniformity" is only partial since there is great variability between individuals as shown by the standard deviations for the results displayed in Tables 2 and 3. Although this variability 
may be partly explained by subject age, $\mathrm{BMI}, \mathrm{VO}_{2} \mathrm{max}$, physical activity and travelling velocity, it is not totally remedied by taking into account individual variables (Equations 1 and 2). This testifies to the complex nature of MWC travel, involving unconsidered parameters, such as user technique and training, wheelchair adaptation, strength capacities, efficiency variation with respect to Cs or velocity (Cooper, 1990; Paré et al., 1993; Van der Woude et al., 2001). In the present study it was not possible to monitor accurately power unbalance between the 2 upper limbs and MWC speed and trajectories. This was due to space limitations in the experimental corridor and impossibility to equip the MWC of each subject. In consequence, the effects of biomechanical factors of the MWC movement are not considered while they could explain part of the individual variability. Our choice of 4 Cs $(0$, 2, 8 and $12 \%$ ) was made to try to understand this complexity, built a strain model and to take in account the $2 \%$ regulatory reference slope adopted in many countries (McMillen et al., 1999) and the acceptable Cs of $10 \%$ (Kockelman et al., 2001) which explains the choice of 8 and $12 \% \mathrm{Cs}$ as upper anchor of the strain model. The Vi $\left(0.97 \mathrm{~m} . \mathrm{s}^{-1}\right)$ is used fairly conventionally (Brubacker et al., 1986; Mukherjee and Samanta, 2001) and was easy to be maintained constant. The a priori decision to perform 6 laps has been validated since it allows 3 stable laps from physiological and velocities point of view.

\subsection{Subjects characteristics}

The 25 active male subjects had a mean $\mathrm{VO}_{2} \max$ of $25.0(5.5) \mathrm{ml} \cdot \mathrm{kg}^{-1} \cdot \mathrm{min}^{-1}$, which compares with the highest data in the literature for paraplegic MWC users who are not sportsmen (Van der Woude et al., 2001; Bhambhani, 2002) and exceeds the most frequently quoted values between 15 and $25 \mathrm{ml} \cdot \mathrm{kg}^{-1} \cdot \mathrm{min}^{-1}$ (Hjeltnes, 1986; Figoni, 1984; Veeger et al., 1991). In a less active population than that studied, Cs generated strains would undoubtedly be greater than those observed in the present study. While at Vc, the $12 \%$ Cs represents an energetic strain of $52 \%$ in the study population (Table 3), it would represent $75 \%$ of the maximum capacity for a less active population with a VO2max of only $20 \mathrm{ml} \cdot \mathrm{kg}^{-1} \cdot \mathrm{min}^{-1}$. Cs consequences would undoubtedly be even more constraining for a more fragile, older and less active population.

The results reveal the surprising effects of injury level on Vc and RQ. Subjects with "high" level injuries, who have no functional abdominal musculature, in fact chose a mean Vc that was significantly $(\mathrm{p}<0.05)$ faster $\left(1.25 \mathrm{~m} . \mathrm{s}^{-1}\right)$ than those with "low" level injuries $\left(1.18 \mathrm{~m} . \mathrm{s}^{-1}\right)$. This difference is significant for all Cs. The literature offers no explanation for this phenomenon. Maintaining a straighter trajectory may require users to travel faster. Lack of 
trunk stability could also cause paraplegics with "high" level injuries to lean more on the handrails to keep in balance, which would also result in a higher Vc. Moreover, the trunk flexion amplitude should be greater for a "high" level injury (Chow et al., 2000). These hypotheses could not be verified in this study. Even lower RQ for "high" level injured users could be interpreted as less muscles involved or less respiratory difficulties for them as for the "low" level injured users. Thus, trunk flexion could be used to reduce energetic and respiratory strains.

The Vc is significantly different for $0 \%$ and $2 \% \mathrm{Cs}$, yet no other result reveals a difference between travelling on the flat and over a $2 \%$ Cs. This result makes $\mathrm{Vc}$ a powerful strain indicator for assessing the difficulty of a travelling condition.

The exertion perceived by the subjects with "low" level injuries (RPE =9.9) was higher $(\mathrm{p}<0.001)$ than that perceived by subjects with "high" level injuries (RPE $=8.5$ ), who nevertheless travelled faster without significantly different energetic $(p>0.5)$ or cardiac ( $>0.3$ ) strains. The day-to-day life of a paraplegic with a "high" level injury is more trying and complex than that of a paraplegic with a "low" level injury. The former could sustain a higher difficulty set-point, which would allow him to confront more easily an identical constraint and have a more positive perception of the laboratory situation than the user with a "low" level injury. Furthermore, depending on the experimental condition, a "high" injury level does not always cause significant alteration in capacities (Vanlandewijck et al., 2011). These factors, which have not been demonstrated in this study, could explain the exertion perception differences in relation to injury level.

\subsection{Physiological strains}

Between the situation at Vi with a $0 / 2 \% \mathrm{Cs}$ and at $\mathrm{Vc}$ with a $12 \% \mathrm{Cs}$, the mean cardiac strains are multiplied by 2.5 (Table 2) and the energetic strains by 3 (Table 3). More precisely, the 0 to $12 \% \mathrm{Cs}$ multiplies the strains by 2 and the change from Vi to Vc multiplies them by 1.5 . Except for the $12 \% \mathrm{Cs}$, the subjects' $\mathrm{HR}$ and $\mathrm{VO}_{2}$ strains remain moderate. For comparison, the cardiac strains in this study are significantly lower than those measured on a flat surface at similar velocities: 127 bpm (Mukherjee and Samanta, 2001). The values of HR, ACC and RCC measured at Vc for a given Cs condition are very close the values measured for the higher Cs condition at Vi. As an example, the ACC at Vc for a $0 / 2 \% \mathrm{Cs}$ is 33.7 (12.9) bpm and is 34.5 (14.0) bpm at $\mathrm{Vi}$ for an $8 \%$ Cs. Thus, it is important to inform MWC users that their velocity is a major strain factor and must be adapted to the environment. The relative energetic cost is equivalent to the relative cardiac cost (Tables 2 and 3). The energetic cost per 
meter $(\mathrm{ECm})$ is related to the travelling velocity. Under the $0 / 2 \% \mathrm{Cs}$ condition, $\mathrm{ECm}$ is 93

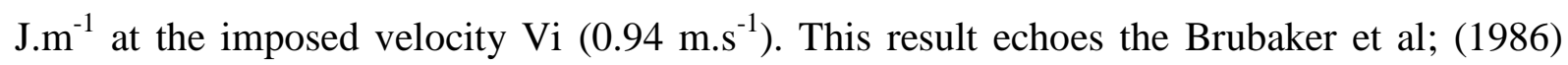

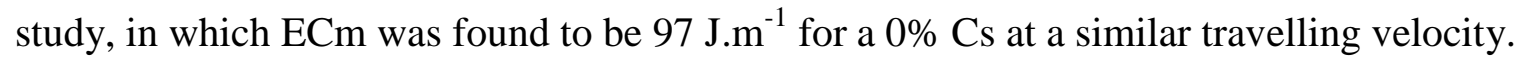

Subjective strains, at the opposite of the objective ones are not significantly different in relation to the travelling velocity on the same Cs. Choosing a so-called "comfortable" velocity causes the subjects to sustain an increase in cardio-respiratory strain, which is not subjectively perceived. Velocity control would appear to minimise the perceived exertion, but may expose the subject to a risk of overload in terms of physiological strains.

\subsection{Comparison with literature data}

Studies that have focused on Cs have not addressed the physiological aspect or have, but based on a few subjects. To validate the data provided by this study, we can compare them with physiological cost data for flat ground. Table 4 consolidates the ACC, $\mathrm{cVO}_{2}\left(\mathrm{ml} \cdot \mathrm{kg}^{-1} \cdot \mathrm{m}^{-1}\right)$ values with respect to travelling velocity on the flat. The studies retained were conducted on a minimum of 9 subjects and involved measuring the $\mathrm{HR}$ and/or $\mathrm{VO}_{2}$.

\section{Table 4 about here}

Results in table 4 show very close energetic costs per meter and weight. When the condition on carpet is not considered, the mean cVO2 cost is $0.134(0,015) \mathrm{ml} \cdot \mathrm{kg}^{-1} \cdot \mathrm{m}^{-1}$. The small differences observed in table 4 can probably be related to subject fitness, travelling conditions or MWC technology. From these results it is possible to compute a very significant relationship between energetic cost and velocity $\left(\mathrm{m} \cdot \mathrm{s}^{-1}\right)$ which is:

$$
\mathrm{cVO} 2=7.5 \mathrm{~V} \quad\left(\mathrm{r}^{2}=0.93, \mathrm{p}<0.001\right) .
$$

This relationship shows that the results of the present study are strongly in accordance with the other ones in table 4. Indeed, the V slope in equation 2 is the same as that from the whole results of table 4. The Wolfe et al. (1977) results in the table put in light the important effect of carpet versus concrete ground on energetic cost.

Hildebrandt et al. (1970) study, conducted on a widely varied population, suggests equivalents in watts (W) of travelling on flat ground in a MWC $(18 \mathrm{~kg}+70 \mathrm{~kg}$ subject) at velocities of $0.3 \mathrm{~m} . \mathrm{s}^{-1}(2 \mathrm{~W}), 0.55 \mathrm{~m} . \mathrm{s}^{-1}(4 \mathrm{~W}), 0.8 \mathrm{~m} . \mathrm{s}^{-1}(6.5 \mathrm{~W})$ and $1.1 \mathrm{~m} . \mathrm{s}^{-1}(11 \mathrm{~W})$, i.e. an equivalent of 8.7 and $16 \mathrm{~W}$ at $\mathrm{Vi}$ and $\mathrm{Vc}$ respectively. For these authors, the efficiency on the flat lies between $5 \%$ and $8 \%$. In this study, the mean energetic cost of travelling on flat ground is $100 \mathrm{~W}$ at $\mathrm{Vi}$ and $182 \mathrm{~W}$ at Vc, i.e. an efficiency of $8.7 \%$ for both velocities, which 
corresponds to a normal result in view of MWC progress, along with the capacities of our study subjects (Van der Woude et al., 1988).

Finally, a number of studies (Van der Woude et al., 1989; Van der Woude et al., 2001) have enabled relationships between ACC (bpm) and $\mathrm{VO}_{2}\left(\mathrm{ml} \mathrm{kg}^{-1} \cdot \mathrm{min}^{-1}\right)$ with respect to velocity $\left(\mathrm{V}\right.$ in $\mathrm{m} \cdot \mathrm{s}^{-1}$ ) and slope $\left(\mathrm{S}\right.$ in \%) to be derived in the form: $\mathrm{ACC}=31.4 \mathrm{~V}+12.1 \mathrm{~S}$ and $\mathrm{VO}_{2}=$ $10.1 \mathrm{~V}+3.8 \mathrm{~S}$. Based on these relationships, $1 \%$ slope increases the ACC by $12 \mathrm{bpm}$ and the $\mathrm{VO}_{2}$ by $3.8 \mathrm{ml} \cdot \mathrm{kg}^{-1} \cdot \mathrm{min}^{-1}$. From the results of the present study (equation 1 and 2) Cs will be $8.3 \%$, based on the energetic cost, and $5.3 \%$, based on the cardiac cost, to reach the strains at $1 \%$ slope. These results do not agree with the data provided by Chesney and Axelson (1996), who considered that a $1 \%$ slope induces a power equivalent to a $3 \% \mathrm{Cs}$, in other words a cost that is 2 times higher than that extrapolated from the results of this study. The differences between Chesney and Axelson (1996), Richter et al. (2007), Van der Woude et al. (1989) results and ours explain that cardio-respiratory strains cannot be compared to physical strains, at least when propelling a MWC. Using only the later to model strains can involve large and dangerous errors. MWC literature focuses, above all, on the technical and biomechanical data for improving exertion efficiency (Van der Woude et al., 2001) and on the maximum capacities of sportsmen in MWCs (Huonker et al., 1998; Paré et al., 1993; Van der Woude et al., 2001; Veeger et al., 1991). The main aim of MWC studies conducted between 1975 and 1995 was to improve wheelchairs by taking advantage of the wheelchair sports boom (Cooper, 1990). During this period, Boston (USA) and Oita (Japan) marathon winning times dropped from over 2.5 hours to less than 1.5 hours. This progress was made possible by improving the technical and technological characteristics of wheelchairs (weight, stabilities, wheels, propulsion, etc.) and adopting efficiency optimising postures (Van der Woude et al., 2001). This explains why physiological data have been so little measured on large numbers of habitual MWC users since research directed towards technical and mechanical data effectively revealed much more refined improvements than physiological data (Van der Woude et al., 2001). The significant effect of a $2 \%$ Cs on Vc supports this idea, even though it does not alter the strains.

\subsection{Strain model}

Observation of the data illustrated in Figure 1 shows that the relationship between Cs and both physiological costs can be considered linear (Chesney and Axelson, 1996, Kockelman et al., 
2001). If all variables are otherwise constant, the mean Cs (in \%) cost can be quantified using the following equations:

$$
\begin{array}{ll}
\mathrm{cVO}_{2}=4.6+0.4 \mathrm{Cs} & \mathrm{n}=583, \mathrm{r}=.51 \\
\mathrm{ACC}=25.6+2.0 \mathrm{Cs} & \mathrm{n}=568, \mathrm{r}=.54
\end{array}
$$

If we consider that a 50\%-of-maximum strain can be easily maintained for several hundred meters (long term) and that a 75\%-of-maximum strain can be maintained for several tens of meters (short term), we can establish long- and short-term Cs limits based on the 2 physiological costs (Monod and Kapitaniak, 2009). For energetic cost $\left(\mathrm{VO}_{2}\right.$ rest $=4.1 \mathrm{ml} \cdot \mathrm{kg}^{-}$

${ }^{1} \cdot \mathrm{min}^{-1}$ ) users with a $\mathrm{VO}_{2} \max$ of $15 \mathrm{ml} \cdot \mathrm{kg}^{-1} \cdot \mathrm{min}^{-1}$ can travel on a $2 \% \mathrm{Cs}$ for several hundred of meters and can travel several tens of meters on a $8 \%$ Cs. If their $\mathrm{VO}_{2} \max$ is $20 \mathrm{ml} \cdot \mathrm{kg}^{-1} \cdot \mathrm{min}^{-1}$, which is undoubtedly the most common among these wheelchair users, they can confront a $19 \%$ short-term Cs, potentially causing a major risk of imbalance. On the other hand, they will be capable of travelling over no more than an $8 \% \mathrm{Cs}$ in the long term. For subjects with a $\mathrm{VO}_{2} \mathrm{max}$ of $25 \mathrm{ml} \cdot \mathrm{kg}^{-1} \cdot \mathrm{min}^{-1}$, there is no short-term limitation and the long term one $(15 \%)$ is risky. For higher $\mathrm{VO}_{2} \max$ values, $\mathrm{Cs}$ limitation is no longer rational. The cardiac strains of the subjects in this study were too low to be able to derive a credible limiting model based on HR since no Cs limit was less than $12 \%$. However, if an ACC of $30 \mathrm{bpm}$ would be a cardiac cost limit (Monod and Kapitaniak, 2009), this would only be respected if the Cs was less than $2 \%$.

\section{Conclusion}

The results of this study show that: i) a $2 \%$ Cs was indistinguishable from flat ground in terms of cardio-respiratory and subjective strains, ii) the physiological strain increases linearly with Cs, iii) an $8 \%$ Cs is subjectively sensitive and impose noteworthy physiological costs and do not allow the RQ to stabilise, iv) a $12 \%$ Cs is unachievable for some users and should therefore be prohibited, v) limiting Cs at $8 \%$ enables the subjects taking part in this study to remain below $50 \%$ of their functional capacities.

These limits cannot be generalised. For users with low cardio-respiratory capacities, a model derived from the results of this study shows that the $2 \%$ Cs limit allows all MWC users to travel.

In practice, an environment in which there are no $8 \% \mathrm{Cs}$ and there is a trend for compliance with the regulatory limit of $2 \%$ should encourage a great majority of people in MWCs to travel. These conditions allow acquisition of independence, conservation of 
functional capacities and promotion of health. Furthermore, they would favour integration of employees in MWCs.

\section{Acknowledgements}

Authors wish to thank the subjects of the study for their interest and willful involvement and Mrs Bruno Corazzini, Gérard Didry, Jean-Charles Guelin and Olivier Remy for their technical help and support. 


\section{References}

Bhambhani, Y., 2002. Physiology of wheelchair racing in athletes with spinal cord injury. Sports Med. 32/1, 23-51.

Borg, G., 1998. Borg's perceived exertion and pain scales. Human Kinetics, Champaign IL.

Brubaker, C.E., McLaurin, C.A., McClay, I.S., 1986. Effects of side slope on wheelchair performance. J Rehabil Res Dev. 23, 55-57.

Burnham, R.S., Steadward, R.D., 1994. Upper extremity peripheral nerve entrapments among wheelchair athletes: Prevalence, location, and risk factors. Arch Phys Med Rehabil. 75, 519524.

Chesney, D.A., Axelson, P.W., 1996. Preliminary test method for the determination of surface firmness. IEEE Trans Rehabil Eng. 4/3, 182-187.

Chow, J.W., Millikan, T.A., Carlton, L.G., Chea, W-S., Morse, M.I., 2000. Effect of resistance load on biomechanical characteristics of racing wheelchair propulsion over a roller system. J Biomechanics, 33, 601-608.

Collins, E.G., Gater, D., Kiratli, J., Butler, J., Hanson, K., Langbein, W.E., 2012. Energy cost of physical activities in persons with spinal cord injury. Med Sci Sports Exerc. 42/4, 691-700.

Cooper, R.A. 1990. Wheelchair racing sports science: a review. J Rehabil Res and Develop. 27/3, 295-312.

Cooper, R.A., Teodorski, E.E., Sporner, M.L., Collins, D.M., 2011. Manual wheelchair propulsion over cross-sloped surfaces: a literature review. Assistive technology: the official journal of RESNA. 23/1, 42-51.

Figoni, S.F., 1984. Spinal cord injury and maximal aerobic power. Amer Corr Ther J. 38/2, 44-50. 
Haisma, J.A., Van der Woude, L.H.V., Stam, H.J., Bergen, M.P., Sluis, T.A.R., Bussmann, J.B.J., 2006. Physical capacity in wheelchair-dependent persons with a spinal cord injury: a critical review of the literature. Spinal Cord. 44, 642-652.

Hjeltnes, N., 1986. Cardiorespiratory capacity in tetra and paraplegia shortly after injury. Scand J Rehab Med. 1986, 18, 65-70.

Hilbers P.A., White T.P., 1987. Effects of wheelchairs design on metabolic and heart rate responses during propulsion by persons with paraplegia. Phys. Ther. 67/9, 1355-1358.

Hildebrandt, G., Voigt, E.D., Bahn, D., Berendes, B., Kroger, J., 1970. Energy costs of propelling wheelchair at various speeds: cardiac response and effect of steering accuracy. Arch Phys Med Rehabil. 51/3, 131-136.

Huonker, M., Schmid, A., Sorichter, S., Schmidt-Trucksäb, A., Mrosek, P., Keul, J., 1998. Cardiovascular differences between sedentary and wheelchair-trained subjects with paraplegia. Med Sci Sports Exerc. 30/4, 609-613.

Kockelman, K., Zhao, Y., Blanchard-Zimmermann. C., 2001. Meeting the intent of the ADA in sidewalk cross slope design. J Rehabil Res Develop. 38/1, 101-110.

Leicht C.A., Tolfrey K., Lenton J.P., Bishop N.C., Goosey-Tolfrey V.L., 2013. The verification phase and reliability of physiological parameters in peak testing of elite wheelchair athletes. Eur J Appl Physiol. 113, 337-345.

Lidal, I.B., Huynh, T.K., Biering-Sørensen, F., 2007. Return to work following spinal cord injury: a review. Disabil Rehabil. 29/17, 1341-1375.

Longmuir, P.E., Freeland, M.G., Fitzgerald, S.G., Yamada, D.A., Axelson, P.W., 2003. Impact of running slope and cross slope on the difficulty level of outdoor pathways. A comparison of proposed design guidelines and user perceptions. Environment and Behavior. 35/3, 376-399. 
McMillen, B., Axelson, P.W., Chesney, D.A., Galvan, D.V., Kirschbaum, J.B., Longmuir, P.E., Lyons, C., Wong, K.M., 1999. Designing sidewalks and trail for access. Part I and II: Review of existing guidelines and practices. US Dept Transportation. 169 pp.

Mercer, J.L., Boninger, M., Koontz, A., Ren, D., Dyson-Hudson, T., Cooper, R., 2006. Shoulder joint kinetics and pathology in manual wheelchair users. Clinical Biomechanics 21, 781-789.

Meyers, A.R., Anderson, J.J., Miller, D.R., Shipp, K., Hoenig, H., 2002. Barriers, facilitators, and access for wheelchair users: substantive and methodologic lessons from a pilot study of environmental effects. Social Science and Medicine. 55, 1435-1446.

Monod, H., Kapitaniak, B., 2009. Ergonomie. $2^{\text {nd }}$ ed, Masson eds, Paris, 286 pp.

Mukherjee, G., Samanta, A., 2001. Physiological response to the ambulatory performance of hand-rim and arm-crank propulsion systems. J Rehabil Res Develop. 38/4, 391-399.

Paré, G., Noreau, L., Simard, C., 1993. Prediction of maximal aerobic power from a submaximal exercise test performed by paraplegics on a wheelchair ergometer. Paraplegia. 31, 584-592.

Richter, W.M., Rodriguez, R., Woods, K.R., Axelson, P.W., 2007. Consequences of a cross slope on wheelchair handrim biomechanics. Arch Phys Med Rehabil. 88, 76-80.

Tahamont, M., Knowlton, R.G., Sawka, M.N., Miles, D.S., 1986. Metabolic responses of women to exercise attributable to long term use of a manual wheelchair. Paraplegia. 24/5, 311-317.

Van der Woude, L.H.V., Hendrich, K.M.M., Veeger, H.E.J., Van Ingen Schenau, G.J., Rozendaal, L.A., De Groot, S., Hollander, A.P., 1988. Manual wheelchair propulsion; effects of power output on physiology and technique. Med Sci Sports Exerc. 20/1, 70-78.

Van der Woude, L.H.V., Veeger, H.E.J., Rozendal, R.H., Sargeant, A.J., 1989. Optimum cycle frequencies in hand-rim wheelchair propulsion. Eur J Appl Physiol. 58, 625-632. 
Van der Woude, L.H.V., Veeger, H.E.J., Dallmeijer, A.J., Janssen, T.W.J., Rozendaal, L.A., 2001. Biomechanics and physiology in active manual wheelchair propulsion. Medical Engineering \& Physics. 23, 713-733.

Van Drongelen, S., De Groot, S., Veeger, H.E.J., Angenot, E.L.D., Dallmeijer, A.J., Post, M.W.M., Van der Woude, L.H.V., 2006. Upper extremity musculoskeletal pain during and after rehabilitation in wheelchair-using persons with a spinal cord injury. Spinal Cord. 44, 152-159.

Vanlandewijck, Y.C., Verellen, J., Beckman, E., Connick, M., Tweedy, S.M., 2011. Trunk strength effect on track wheelchair start: implications for classification. Med Sci Sports Exerc. 43/12, 2344-2351.

Van Velzen, J.M., De Groot, S., Post, M.W.M., Slootman, J.H.R., Van Bennekom, C.A.M., Van der Woude, L.H.V., 2009. Return to work after spinal cord injury. Is it related to wheelchair capacity at discharge from clinical rehabilitation? Am J Phys Med. 88/1, 47-56.

Veeger, H.E.J., Hadj Yahmed, M., Van der Woude, L.H.V., Charpentier P., 1991. Peak oxygen uptake and maximal power output of Olympic wheelchair-dependent athletes. Med Sci Sports Exerc. 23/10, 1201-1209.

Vignier, N., Ravaud, J.F., Vinance, M., Lepoutre, F.X., Ville, I., 2008. Demographics of wheelchair users in France: results of national community-based handicaps-incapacitésdépendance surveys. J Rehabil Med. 40, 231-239.

Wilmore, J.H., Costill, D.L., 2004. Physiology of Sport and Exercise. $3^{\text {rd }}$ ed. Human Kinetics eds, Champaign, Illinois.

Waters R.L., Lunsford B.R., 1985. Energy cost of paraplegic locomotion. The J Bone Joint Surg. 67-A/8, 1245-1250.

Wolfe G.A., Waters R., Hislop H.J., 1977. Influence of floor surface on the energy cost of wheelchair propulsion. Physical Therapy. 57/9, 1022-1027. 